\title{
The lack of eye care preventive services in public health leads to an increase of progressive blindness
}

\author{
Clecilene Gomes CARVALHO ${ }^{1}$ \\ Ivanir da Silva Batista de SOUZA ${ }^{2}$ \\ Sérgio Ricardo MAGALHÃES ${ }^{3}$
}

\begin{abstract}
${ }^{1}$ Graduated in Nursing by College 'Universidade do Vale do Rio Verde' (UNINCOR), campus Betim city. Member Association of Pulmonary Hypertension of the state Minas Gerais (AMIHAP). Post-graduation student in Multifocal Psychology. E-mail: clecilene@globo.com

${ }^{2}$ Graduated in Nursing by College 'Universidade do Vale do Rio Verde' (UNINCOR), campus Betim city.

E-mail: ivanir100@gmail.com

${ }^{3}$ Teaching of Nursing course of College 'Universidade do Vale do Rio Verde' (UNINCOR), campus Betim city. PhD in Biomedical Engeneering. E-mail: sergio.magalhães@unincor.edu.br
\end{abstract}

\begin{abstract}
Blindness is a serious public health problem. In Brazil, it is estimated that there are 1 million 100 thousand blind and about four million visually impaired, $80 \%$ of blindness in the world are predictable causes and / or treatable. Considering the epidemiological importance of eye diseases and magnitude of blindness in Brazil, saw the need for a literature review in order to understand the problem for future interventions. The survey results showed that: the main causes of blindness are diabetic retinopathy, macular degeneration, cataracts, glaucoma, and an alarming number of childhood blindness due to various causes, the progressive increase of blindness is attributed to several factors, in particular, the lack eye care, lack of infrastructure, organization, financial resources, which are aggravated by poverty, misinformation, inequality of the population and the absence / lack of educational efforts, despite the alarming statistics and the gradual increase in blindness, has no effective measure to control it. The model of care in ophthalmology curative until then, highlights the need for urgent action to ensure eye care in primary health care, thus allowing to ensure the completeness, quality, equity in service of disease prevention, promotion, recovery and rehabilitation of eye health .
\end{abstract}

Keywords: Blindness. Eye care. Promotion. Prevention.

\section{INTRODUCTION}

The tenth review of the international classification of diseases and problems related to health (CID-10) states that a person has vision under the normal (VSN) or low vision, when the corrected vision acuity in the best eye is under than $20 / 70$ and bigger than or the same as 20/400 and blindness when these values are under 20/400 (SILVA, MATOS, LIMA, 2010).
Blindness is one of the most serious problems of Public Health. Each five seconds one person becomes blind in the world and one child each minute. There are in the world about 286 million of people who have vision problems, among them 39 million are blind and 246 million have serious or moderate disabling. In Brazil, the number of blind people is estimated on 1, 1 million and about 4 million eyesight disabled. It is alarming, because $80 \%$ of blindness in the world is a 
result of predictable and/or treatable causes (OMS, 2011; SPO, 2009).

Researches done by OMS stated that, if global and regional initiatives wouldn't taken, in 2020 will be in the world 75 million blind people and more than 225 million people with low eyesight and $90 \%$ of these people are inhabitants of from underdeveloped or developing countries (SOB, 2009).

A sector of the population formed by individuals who have eye disorder already in a under clinic or moderate phase and of hard identification, it has unnamed proportion. It is supposed that those individuals are"the base of the iceberg", that in a figurative language means the loss of eyesight. Blindness is highly disabling, because restrict the quality of life according to the intellectual, productive, social economic and psychological point of view. Blindness, visual acuity under 0,05 and visual field under 10 degrees, it's a condition that provokes much suffering. Loss of professional productivity, the difficulty of insertion in the job market, loss of self-esteem and family disruption are only some of the aspects that come from blindness, which even represents a relevant social-medical problem, since the rehabilitee and assistance to a blind person have a high economic cost (COSTA, 2010).

Considering the epidemic importance of the eye diseases and the wideness of the blindness in Brazil and in the world, it is saw the necessity of bibliographic review. The aim is to identify the main causes of blindness, the reason of the increasing of the disease and the strategies taken by Public Health Services to stop it in advance, minimize the eyesight loss and promote eye health.

It is waited that this job could be a subsidy for discussions and reflections about the eye assistance model until now curativist, assuming a new concept of health, a new assistance model, developing temporary actions of public responsibility, with social participation, in order form a net of services by region and following an hierarchy to eye assistance.

\section{METODOLOGY}

This is a study of bibliographic review, wide and detailed, critical analysis of the current publications of eye care in public health that approached publication between 2000 and 2011 by systematic searches using electronic data banks. The data were collected on the Health Minister website and on the index MEDLINE, PubMed, LILACS, SCIELO (Scientific Electronic Library Online) and BIREME.

The objectives served to classify and to structure the bibliographic review. Since classified and structured, serves as basis for a wide analyses of the subject. The following key words were used: blindness causes; progressive increasing of blindness; eye assistance by SUS (Unique System of 
Health); eye care quality; lack of eye assistance.

The preliminary analysis resulted in 44 publications, but only 17 were selected because they clarified better the questions done about the blindness problem.

\section{PRESENTATION OF THE RESULTS}

\subsection{Main causes of the blindness}

Diabetic retinopathy is one of the main causes, in Brazil there are about 11,5 million of people who have diabetes. In this total, $5 \%$ are children. The diabetic patient has 29 times more chaces of develop blindness. It is estimated that $80 \%$ of the diabetic patients will present any level of retinopathy after 25 years of the disease. And, what is the most worrying: from 5 up to $8 \%$ of the blind people in the world are in consequence of diabetic retinopathy. In Brazil, this number is even serious: the diabetic retinopathy is responsible for up to $12 \%$ of the new blindness cases and, according to studies, this kind of blindness is irreversible.

About 3 million of Brazilians over 60 years old suffer eye degeneration related to the age. The occurrence of cataract in the population in general in Brazil between 50 and 65 years old is of $17,6 \%$ and it increases to $47,1 \%$ between 65 and 75 years old. Over 75 years old it increases to $73 \%$. If we consider that Brazilian population over 60 years old in 2007 corresponded to $18,6 \%$ of the population, it is predicted that there are in Brazil 3,287.509 patients with cataract, and, among them, 611 thousand are completely blind.

Glaucoma is the third main cause of blindness in Brazil. Its occurrence is between 1 to $2 \%$ in the population in general, increasing after 40 years old, and could reach 6 or $7 \%$ after 70 years old. The disease occurs in the two eyes in the most of the cases. The hereditary nature gives ten times more chances to the relatives in first degree to develop the disease.

Blindness in children is also much worrying in Brazil. It occurs between 1 and $1,5 \%$ in each one thousand children. Comparing with developed countries, this number is, at least, five times smaller. There are many causes: amblyopia, refractive errors, cataracts, congenital toxoplasmosis, rubella, andretinopathy of prematurity. All of them could be avoided with prenatal exam and many times with the treatment in the ITU, as it happens to retinopathy in prematures. 
The real magnitude of blindness and visual inability tends to be bigger than estimates indicate, because there is a lack of detailed and precise epidemiological information (OMS, 2011).

\subsection{Why the progressive increasing of blindness}

The progressive increasing of the blindness and visual inability in the World can be related, in special, to the growing of the population, to the increasing of life's expectation, to the shortage of specialized services, to the difficulties of population of access to eye care services, to the economic difficulties and, to the absence/insufficiency of educational efforts that promote the adoption of preventive behaviors (COSTA, 2010).

In Brazil, the lowest sectors of the population, as the inhabitants of the less developed regions, present more problems related to absence of blindness prevention.

People don't know that there are diseases that cause irreversible blindness that can be treated, before blindness is settled. A study held in a group called HiperDia (diabetics and hypertension blood people), patients under a high risk to develop glaucoma, in a town in metropolitan area of Belo Horizonte, noticed that $82,6 \%$ of the interviewers didn't know what glaucoma is, an eye disease that over the years, if not treated, can drive to irreversible blindness. People don't have information about eye diseases (CARVALHO et al, 2010).

Cases of blindness are distributed irregularly and concentrate in the developing countries. One of the factors that influence that inequality is the lack of resources organization to the eye care, $80 \%$ of the blind cases could be avoided if it is applying technical and knowledge currently available, to detect in advance and make possible to head eye problems (OMS, 2011).

Because of high necessity of assistance in the eye care, added to the lack of organized services and the difficulty of access of user to eye care service, it is settled a messy and vicious flow in the medical assistance. It is known that the biggest obstacle is not the lack of adequate technology, but in the difficulty on creating good conditions to motivate the people; few access to the services; lack of infrastructure and eye care organization (GENTIL; LEAL; SCARPI, 2003).

3.3 Strategies adopted by public health services to prevent blindness, minimize the loss of vision and eye health promotion 
World Health Organization (OMS) over the decades is worried about settling programs and groups to prevent blindness. The initiative VISION 2020: The right to the vision assumes a global proportion to the elimination of avoidable blindness all over the world until 2020. It is coordinate by OMS and International Agency to Prevent Blindness and has an international society of Non Governmental Organizations, Professional associations, Eye care institutions and corporations (COSTA, 2010; OMS, 2007).

This initiative, as well as adopting the basic strategy of comprehensive eye care, integrated primary health care, includes three components as target activities: specific disease control, human resource development, infrastructure development and appropriate technology (TEMPORINI, KARA, 2004).

If the proposal VISION 2020 would be well succeeded, it is estimated to reduce to 24 million the number of blind people in the world, what will reach 429 million individuals who will have their vision preserved in cases of avoided blindness. This initiative would save US\$ 120 billion in the treatment of eye diseases treatment (COSTA, 2010).

In May, 2008 were published the ordinances 957 and 958 . The first stated the National Politics of Eye care, and the second, redefined the National Politic Elective Surgery Proceedings of Medium Complexity. Both laws draw new directions for eye care in the Unique Health System and established the
Program of fight of prevailed causes of blindness, that make easy carrying out proceedings linked to cataract surgery, to diabetic retinopathy treatment, glaucoma macular degeneration related to age (MINISTÉRIO DA SAÚDE, 2007).

The National Politic of Attention in Ophthalmology define that the basic attention actions must be individual or collective, promotes health and previews damages and recovering, as well as clinic actions to control alterations that lead to eye diseases and the eye diseases themselves, that can be done in this level; these actions must have place in the basic health services net; it also defines that the prevention and treatment plan of ophthalmological diseases must be part of municipal health plans and of the regional development plans of the states and of the federal district (BRASIL, ORDINANCE 957,2008).

The National Politic of elective surgery proceedings outpatient and inpatient of medium complexity, ordering to overcome inequalities of access and the guarantee of the integrality of health care, states that the Policy cover proceedings settled in programs defined as strategic, establishing ways to reduce the wait time for these proceedings and extend the offer to the population (BRASIL, ORDINANCE 958, 2008).

The Ordinance 958, second Article about National policy of elective surgery proceedings of medium complexity outpatient and inpatient has as component, the 
Program to combat blindness causes, defined in the attached 1 and prioritize the following diseases:

A - cataract type A;

B - diabetic retinopathy;

C - glaucoma;

D - age-related macular degeneration is the main blindness cause among patients over 60 (BRASIL, ORDINANCE 958, 2008).

The Ordinance 288/SAS, May, 19, 2008, Article number 5, states that all Units of Specialized Ophthalmology care and the Ophthalmology Reference centers that are accredited must organize a care line in all of the levels of attention that promotes , previews, treat and recovers health; integrates with regional and local health network; offers consultations in ophthalmology, according to the needs of the population, as defined by Health Manager. It also establishes in its paragraph 1, must be performed promoting and previewing actions in ophthalmology that be able to identify and follow families and individuals as it follows:

I - education actions;

II - visual acuity test;

III - medical consultations;

IV - nursing consultation;

$\mathrm{V}$ - Previewing actions to investigate diabetes and hypertension and, that come before specialized care in ophthalmology;
VI - monitoring of counter referenced users by the specialized care units in ophthalmology (BRASIL, ORDINANCE 288/SAS, 2008).

In Minas Gerais, the resolution SES number 1887, may 27, 2009, approves the organization of the Ophthalmology State Network and defines criteria, rules and requirement to deploy it in the state.

The Article 2 of this resolution defines the distribution of services of the State Network in Ophthalmology, observing the integrity of eye care, considering the three levels of care: primary, secondary and tertiary as well understood:

I - Primary: means for primary care in primary care, ie, to undertake actions of individual or collective, focused on health promotion and prevention of damage and recovery, as well as clinical actions for disease control that lead to ocular disorders. And yet, the very eye diseases that can be performed at this level, these actions taking place in the network of basic health services, and the county service territory. II - Secondary Care: means for care in Secondary Care Specialized Care in Medium Complexity in Ophthalmology, namely to carry out specialized diagnostic and therapeutic care and promote patient access to ophthalmologic care procedures of medium complexity, specialized services of quality. In order to achieve positive impact on morbidity and quality of life of SUS, through ensuring equality, and the micro-territory service. 
III - Tertiary Care: means for tertiary care treatment in the Specialized Care Ophthalmic High Complexity, or perform specialized diagnostic and therapeutic care and promote patient access to ophthalmologic care procedures of high complexity, specialized services of quality. In order to achieve positive impact on morbidity and quality of life of SUS, through ensuring equality, and the macro-region service territory (MINAS GERAIS, 2009).

The Brazilian Council of Ophthalmology has acted on several fronts definitely investing in eye health of the population, seeking thereby to improve the attendance rates of significant demand in Ophthalmology, through an administrative and operational interaction among existing programs, such as: Campaign for Visual Rehabilitation Eye to Eye, low Vision Campaign, of Cataract Campaign for Diabetic Retinopathy, Glaucoma Campaign, Campaign for Visual Rehabilitation of INCRA, Campaign for Visual Rehabilitation of Community Development, Campaign for Visual Rehabilitation of Bank of Brazil Foundation, Eye Health Campaign of Rotary and Lions, among others (CBO, 2009).

\section{DISCUSSION}

The bibliographic review evidenced that blindness is among the most serious health problems, and its importance and its greatness and epidemiological importance are unknown, despite of numerical evidences.
It's a big volume of blind and visually impaired. Brazil is in a position which deserves attention. Blindness situation is getting worst. To minimize these numbers, it's necessary exclude or reduce the blindness causes, that is a compromise of $\mathrm{WHO}$, but Brazil is walking to the opposite direction, because it's observed, in the literature is a progressive increasing of blindness over the years (SPO, 2009).

The prediction is that the current number of blind people in the planet is up to 75 million in the year of 2020. It is estimated that $90 \%$ of the blind cases occur in poor areas around the world. This is not different in Brazil. Because exactly in these areas there's a lack of the most important aspect, not only in ophthalmology, but in the health as well, that is the prevention (WHO, 2011; HEALTH MINISTERY, 2007).

The progressive increasing of blindness and visual impairing is related to many factors, especially, to the lack of specialized services in ophthalmology facing an excessive demand in the area, access difficulty for the population to these services, lack of infrastructure, care organization, monetary resources. Factors that are worsen by the poverty, misinformation, inequality in the population and to absence/insufficiency of education efforts that promote the adoption of preventive behavior and detection in advance of eye diseases that drive to visual loss that could be avoided (GENTIL; LEAL; SCARPI, 2003). 
It's highlighted as the main causes of blindness the diabetic retinopathy, macular degeneration, cataract, glaucoma and a worrying number of child blindness of different causes. Theses pathologies were recognized and are considered priorities in the Program of combat to prevalent blindness causes. If they are diagnosed in advance is possible treat them and/or control them previewing thus the blindness. Nevertheless, the increasing number of cases that drive to blindness evidences that the program is not effective, mainly to the basic health attention, where is possible to treat the first signs of diseases (HEALTH MINISTERY, 2007).

There's a huge restrained demand in ophthalmology, in many segments (refraction, cataract, diabetic retinopathy, low vision, glaucoma, among others), as far access difficulty as insufficient covering health system and by the incapacity of the poor population to complete the treatment $(\mathrm{CBO}$, 2009).

It wasn't found articles that prove effectiveness and efficiency of the prevention and promotion action in the area of ophthalmology in the first health care, only isolated actions in schools and sporadic campaigns.

Despite of alarming data and progressive increasing of blindness, there isn't yet, any effective measure to control it. It's seen that only since 2008 were created specific national measures to ophthalmology that lead and support public services in the area (HEALTH MINISTERY, 2007).

As cited in the last paragraph were created some strategically measures to prevent blindness, on the other hand there's a difficulty to set these ordinances, the programs and policies of ophthalmology care. This difficulty can be charge to the lack of available resources and can be proved by the referring blindness data.

We have in Brazil 14.055 ophthalmologists in activity. The number ophthalmologist per inhabitant is the biggest in the world, probably, one for 13.981 people. This relation is much bigger than what is considered as necessary by WHO, that is one to 20 thousand. We can increase this number and offer to the population ophthalmological health care in the levels of few places have. The problem is not the ophthalmologist. There is a lack of governmental policy really concerned to the poor people. Today we do 250 thousand cataract surgeries, an ashamed number, as we have capacity to do 1 million of surgeries. We have an excellent surgery feature from the North to the South of Brazil. Why don't we do more? Because, there's no financing (HEALTH MINISTERY, 2007).

According to the Health Ministery, world statistics show that after the cataract surgery, the patient returns to the community, at least, 4 times a year what the community have spent. And the Unique Health System knows what are the damages and how much it is spent with a blind person. The patient 
changes the quality of life of the whole family and needs an escort almost all the time. The patient stops to produce, becomes dependent and generates more expenses. For 600 Reais, per patient, we can resolve the cataract problem in Brazil, rapidly. If we want to prevent the guy loses his job and has a blindness work, you must perform 5000 operations per 1 million inhabitants. This would, in Brazil, almost 900000 cataract surgeries. So Brazil will no longer operate about 650 thousand people per year. 650,000 are visually impaired per year, for a cost much lower than the Ministry of Health, could be recovered.

To solve the problem of blindness becomes a necessary situational awareness, sensitization and mobilization to create inter ministerial actions, institutional, interdisciplinary, inter professional Inter manager with community participation. You need qualifying assistance in ophthalmology and to promote continuing education of health professionals involved with the implementation of National Policy in Ophthalmology, in accordance with the principles of comprehensiveness and humanization.

The public health programs in ophthalmology should aim to promote eye health, the organization of eye care and rehabilitation of the visually impaired. The eye care should be integrated into primary health care, developing activities to prevent and control specific eye diseases, human resource development, infrastructure and appropriate technology (JEVEAUX, 2008). In case of eye health, the person will seek treatment in the Local Health Unit (LHU) and will be forwarded to the referral service as a medical specialty is ophthalmology and therefore is not treated in primary care. This second appointment may take months or even years to happen, depending on the pent-up demand to be met by services. Unfortunately, there are cases reported and experienced by users to be called for consultation when your case is already aggravated and difficult to resolve, often requiring a new referral to another reference service, more complex. History may repeat itself as the first referral and the user end up aggravating their situation to the point of finally losing his sight. This offense is excessive delay to the Federal Constitution, which establishes the foundation of a democratic country we live in human dignity and health has to be a universal right and a duty of the state have an obligation to provide comprehensive care. Also hurts the Organic Health Law no. 8.080/90 which guarantees access to health services effectively and without any discrimination (LINO, 2007).

According to Sir Jose Alencar, Vicepresident, who died in 2011, the company identifies Ophthalmology in a relevant area of medicine to help humans to enjoy one of the most beautiful and valuable gifts of life: the vision. See the world with its natural beauty, its colors and hues, to see the sunrise, admire 
the light of day, recognize similar, all are gifts from God. Preserve, restore and enhance this sense is a noble mission entrusted to an ophthalmologist. Add your talk that eye health is a right of all and it is the duty of the state to ensure effective eye care, efficiently and effectively guaranteeing a fundamental right of all is the vision (MINISTRY OF HEALTH, 2007).

\section{CONCLUSION}

It is necessary to a full service in ophthalmology to users of the Unique Health System (SUS), adopting a preventive care and eye health promotion in primary care (Primary Health Care and Family Health Strategy). We hope the information contained in this work serve to alert, educate, sensitize and mobilize the many spheres of government, society, health professionals, managers and health managers to the problem of blindness. Which serve as input to discussions and reflections on the model of care in ophthalmology hitherto curative, with a new concept of health, a new model of care, developing cross-cutting actions of public responsibility, social participation, in order to structure a network of regionalized hierarchical and eye care.

It is also organizing a line of integrated and comprehensive care that goes over all levels of care, and improving management, expanding coverage to care for patients with eye diseases, which promotes eye health, prevent the eye diseases, control the conditions that lead to eye problems.

It takes a holistic and dynamic eye care, ensuring the universality, fairness, integrity, social control and so is the primary right to health.

\section{REFERENCES}

BRAZIL. National Press - Gazette of the Republic of Brazil On-16/05/08- DECREE 957 OF 15 MAY 2008 - Establishes the National Policy in Ophthalmology-BrasiliaDF.

\section{BRAZIL. National Press REPUBLIC OF BRAZIL-Gazette of 16/05/08 In-958- ORDINANCE OF 15 MAY 2008 - Redefine the National Policy for Elective Surgical Procedures for Medium Complexity: Ministry of Health, Brasilia-DF.}

BRAZIL. National Press Federative Republic of Brazil - DOU of 20/5/08 ORDINANCE-In288/SAS OF 19 MAY 2008 - Department of Health Care-Brasilia - DF.

CARVALHO, SOUZA Clecilene, Ivanir SILVA AMARAL, Renata; Magalhaes, Sergio. Glaucoma, and dangerous hidden enemy vision: Evaluation of the level of knowledge of diabetes and hypertension, the city of Sao Joaquim de Bicas (MG) on glaucoma. e-Scientia Scientific Journal of the Department of Biological Sciences, Environmental Health and University Center of Belo Horizonte (UNI-BH), Brasília, DF, 3.2, 2612 2010. Available in: $<$ http://revistas.unibh.br/dcbas/viewarticle.ph p?id=65>. Accessed on July 1, 2011.

COSTA, Marcio S.. Health and education in primary eye - a look of citizenship.Dissertation submitted as partial requirement for the degree of Master of Business Administration. Businnes School ISCTE - Lisbon University Institute. 
KIND, R. M, Leal, S. M.R; Scarpi, M. J. Assessment of resolution and satisfaction of customers from a secondary referral service in ophthalmology at the Federal University of Sao Paulo UNIFESP. Arq Bras. Ophthalmology., St. Paul, vol. 66, n. 2, 2003. Available in: http://www.scielo.br/scielo.php?script=sci_art text\&pid=S0004 $27492003000200009 \& \operatorname{lng}=$ pt\&nrm=iso. Accessed April 13, 2011.

JEVEAUX, Giancarlo C.. Prevention of blindness in children 3 to 6 years assitidas the Family Health Program (PSF) of the hill from the German-RJ. Dissertation submitted to the Graduate Program in Family Health, the Teaching Centre of the University Estacio de Sa - RJ. Estásio de Sá University, Rio de Janeiro, 2008.

WHO-World Health Organization - World Sight Day, October 11, 2007 - Available in: http://www.who.int/mediacentre/events/2007/ world_sight_day/en/index.html- Accessed on March 15, 2012.

LINO, L. H-2007 - Optometry in primary care: a proposal for improving the quality of the visual health of the population - Academic Space Magazine - No. 79 - Monthly, December / 2007 Available in: http://www.espacoacademico.com.br/079/ 791 ino.htm Accessed on: April 22, 2010.

MINAS - DEPARTMENT OF STATE HEALTH-SES No. 1887 RESOLUTION OF 27 MAY 2009 - Available in: http://www.saude.mg.gov.br/atos_normativos /resolucoes/2009/resolucao_1887.pdf

MINISTRY OF HEALTH. II national eye health forum 2007 - Perspectives on Brazil IIAvailable in: http://www.saudeocular.org.br/2forumolhares-6.html- Access: April 8, 2012.

WHO-World Health Organization - World Sight Day, October 11, 2007 - Available in: http://www.who.int/mediacentre/events/2007/ world_sight_day/en/index.html- Accessed on
March 152010.

WHO-World Health Organization. World Day of vision 2011.http://www.vision2020.org/main.cfm?ty pe $=$ WSD11 \&objectid $=4298$. Accessed on August 12, 2012.

SILVA, Ana Maria Tavares da Costa Pinto, MATOS, Marta Rebelo de Hercog Baptist; LIMA, Humberto Castro. Low Vision Service of the Brazilian Institute of Ophthalmology and Prevention of Blindness (IBOPC): analysis of patients enrolled in the 1st year of the department (2004). Arq Bras. Ophthalmology., St. Paul, vol. 73, n. 3, June 2010. Available in: $<$ http://www.scielo.br/scielo.php?script=sci_a rttext\&pid=S0004$27492010000300011 \& \operatorname{lng}=$ en\&nrm $=$ iso $>$. acc ess on Aug 14, 2012.

BRAZILIAN SOCIETY OF OPHTHALMOLOGY - World Sight Day: October 8, 2009 - Available in: http://www.sboportal.org.br/site2/ultimasnoti cias/outubro_2009/destaque_07_10_2009.asp Access: April 8, 2012.

SPO - Paraibana Society of Ophthalmology. World Sight Day, October 08.Paraiba, 2009. Available in: http://www.spopb.com.br/noticias.php?id=10 3. Accessed on: April 13, 2012.

TEMPORINI, Edméa Rita, Kara-José, Newton. The Loss of Sight: Strategies for prevention. Arq Bras. Ophthalmology., St. Paul, vol. 67, n. 4, August . Available in: http://www.scielo.br/scielo.php?script=sci_art text\&pid=S0004-27492004000400007 Accessed on: March 12, 2012. 